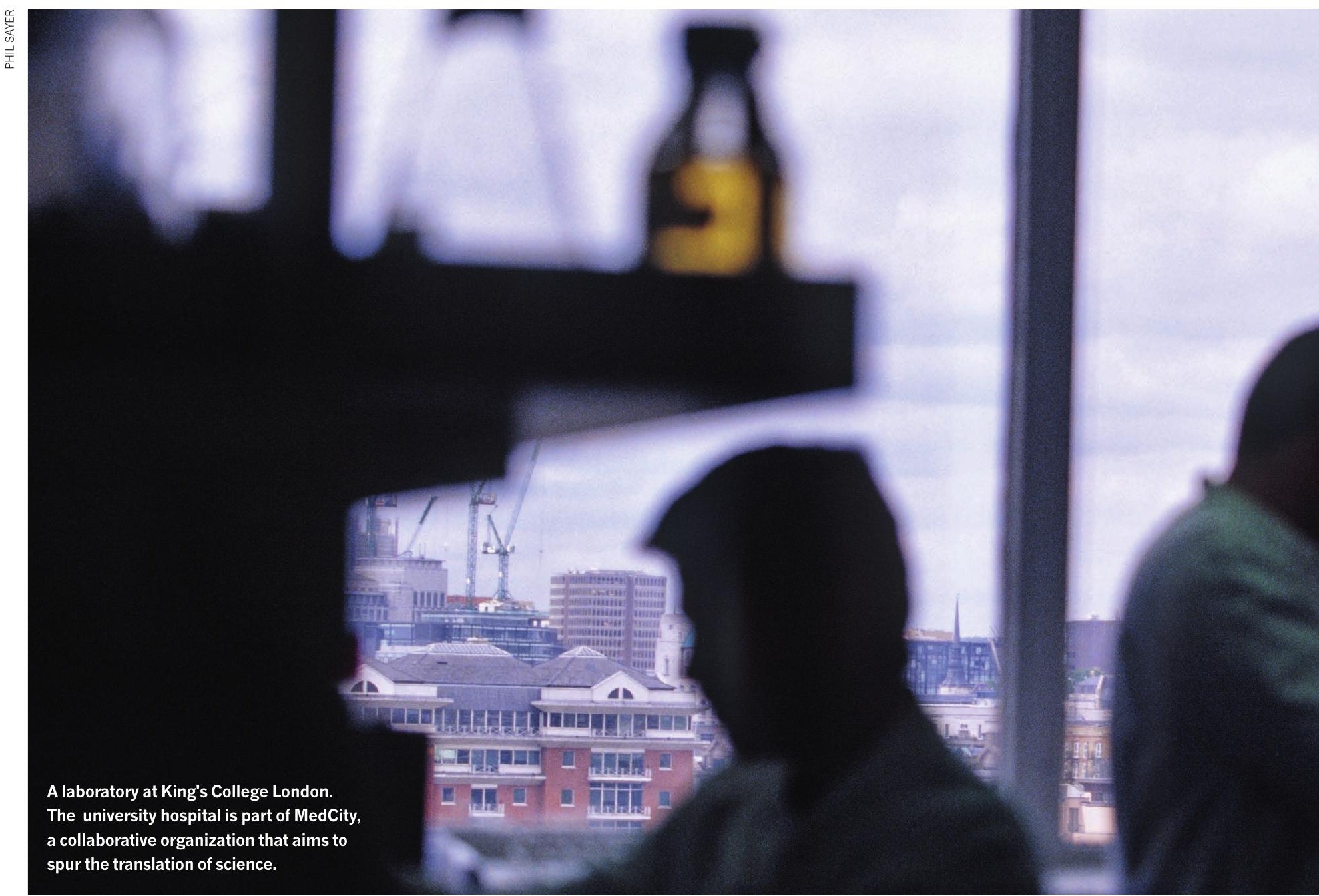

\title{
STEEPED IN SCIENCE
}

\section{For centuries a hub of ideas and trade, London is embracing ambitious developments to boost research and local connections, despite the uncertainty caused by Brexit.}

\section{BY ANNA PETHERICK}

$\mathrm{L}$ ondon has historically been a science megacity. In 1665 it saw the launch of the world's first science journal, Philosophical Transactions. A walk through the West End takes you through the same streets that led to the Broad Street pump on John Snow's map of cholera, his original evidence for the germ theory of disease.

Even as other megacities have risen over the centuries, and with the complications of Brexit looming, London maintains its position as a powerhouse of research output. London has about a third of Shanghai's population, yet London scientists author almost the same share of peer-reviewed publications in the journals tracked by the Nature Index each year. The city centre is less than an hour from both Cambridge and Oxford, forming the central node of the UK's scientific golden triangle.

Though scientists are concerned about the outcome of the Brexit negotiations, particularly on immigration, regulation and the UK's access to European Union research funds, London's business community, mayor and people are overwhelmingly pro-Europe - close to $60 \%$ of Londoners voted to remain in Europe - and are determined to protect their competitive advantages from other European interests.

One of the curious features about science in London is its strong biological focus relative to the rest of the UK. Institutions in London contribute to life sciences papers in the Nature Index as frequently as they contribute to chemistry and physical sciences papers combined. This is thanks, in part, to the UK's three main university hospital systems - King's College London, Imperial College London and UCL located in the city. The latter two rank among the global top 10 in the QS World University Rankings and in the top 40 in the Nature Index.

The London-based medical universities collaborate in various ways. They came together in 2014, along with the Mayor of London's office, to create MedCity, an organization that aims to spur translational life science research. Sarah Haywood, MedCity's CEO, says that medical 


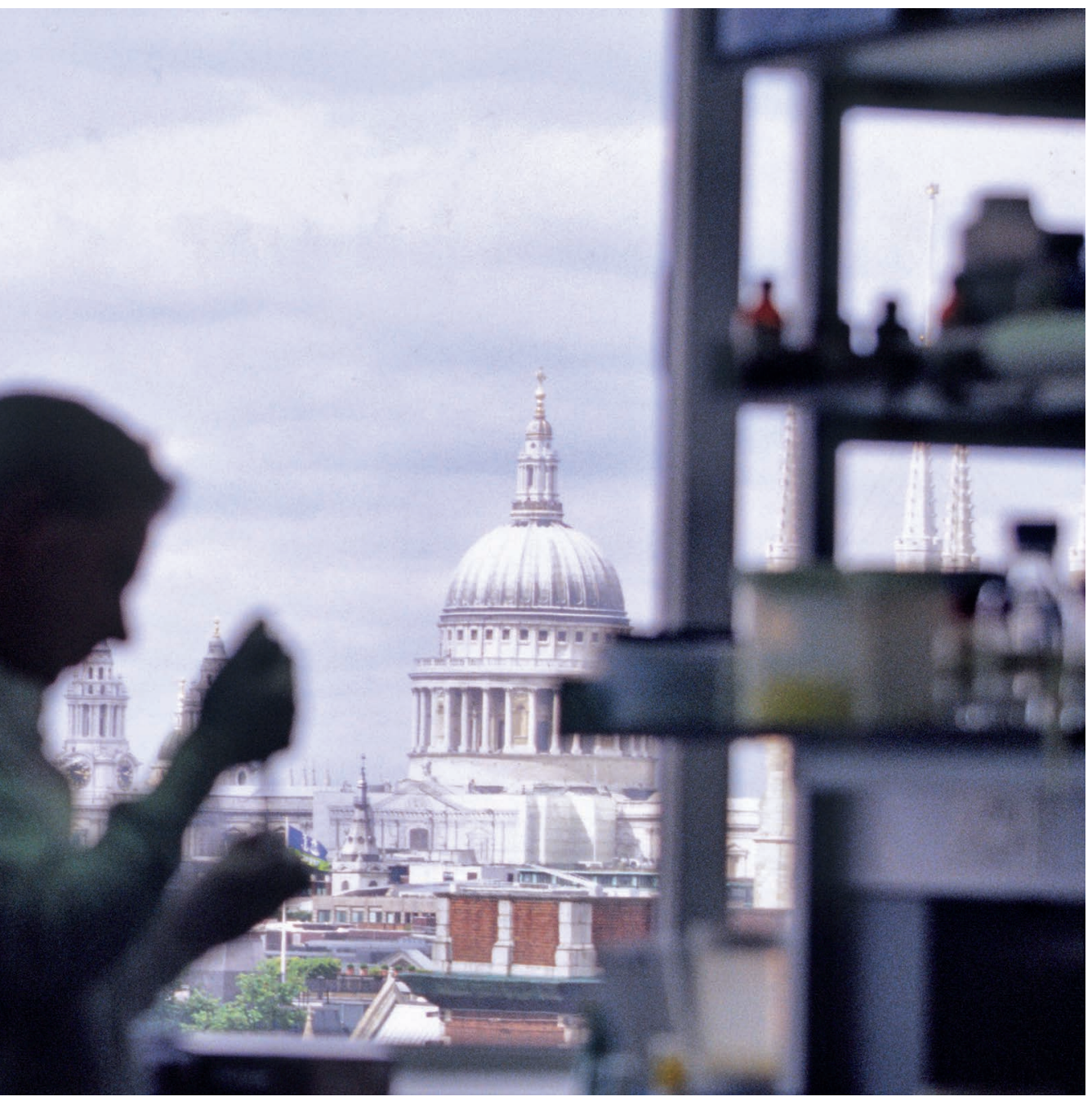

innovation in London benefits from the availability of venture capital, but also from the 8.2 million patients registered with the country's single public health provider, the National Health Service (NHS). While this vast pool of patients represents many opportunities for clinical trials, it also feeds new ideas back into research.

Jeremy Chataway, for example, a neurologist at the UCL Institute of Neurology, is leading trials to repurpose the cheap cholesterol-lowering drug simvastatin for treating patients with multiple sclerosis. Results of the phase-two trial, published in The Lancet in 2014 , found that simvastatin reduced the rate of brain atrophy in patients with an untreatable form of multiple sclerosis, but it also raised new questions about the drug's mechanism of action.

Perhaps the medical universities' most visible collaboration of recent years has been the founding of The Francis Crick Institute, a partnership with the UK's Medical Research
Council, Cancer Research UK and the Wellcome Trust. Last year, the institute opened the doors of its new building in Kings Cross. The building has no demarcated departments in the hope that researchers in disparate biomedical subfields will forge

In a departure from the usual way of operating, the Crick has promised to provide research funding for junior group leaders who go on to take up science jobs elsewhere in the UK. "In this respect we differ from traditional institutes, which hang on to their best people," says Paul Nurse, the Crick's chief executive and director. "We want to act as a pipeline for other institutions, to help build up a critical mass of expertise across the country."

\section{BREXIT TALKS}

If the Crick Institute's recruitment numbers are anything to go by, the looming exit from the EU has not discouraged researchers from flocking collaborations.

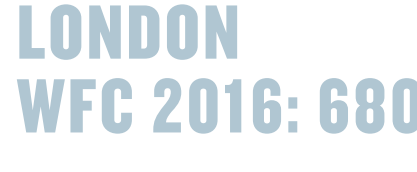

$\begin{array}{ll}\text { Population }^{1} & \mathbf{8 . 7 9 m}\end{array}$

GDP per capita ${ }^{2}$

US\$78,400

R\&D as $\%$ of GDP $^{1,2} \quad \mathbf{0 . 8} \%$

Science doctorates $^{3} \quad \mathbf{3 , 1 0 0}$

Patents granted ${ }^{4}$

1,500

\section{SHARE OF OUTPUT OVER TIME}

London's contribution to the share of authorship in the Nature Index, measured by the share of weighted fractional count (WFC) for that year, compared to the United Kingdom's share.

$\square$ United Kingdom $\square$ London

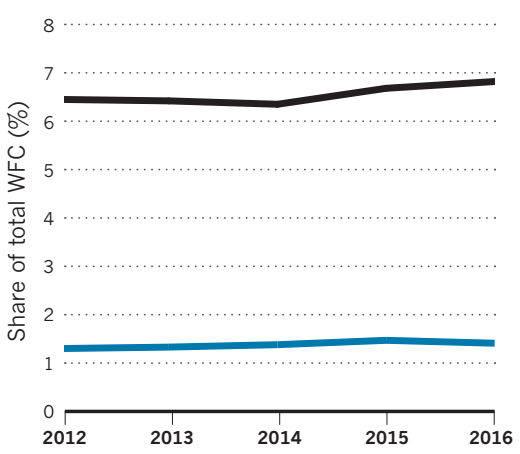

\section{SUBJECT STRENGTHS}

Most of London's contribution to the authorship of papers in the Nature Index is in the life sciences.

United Kingdom $\square$ London

Output is based on WFC 2016

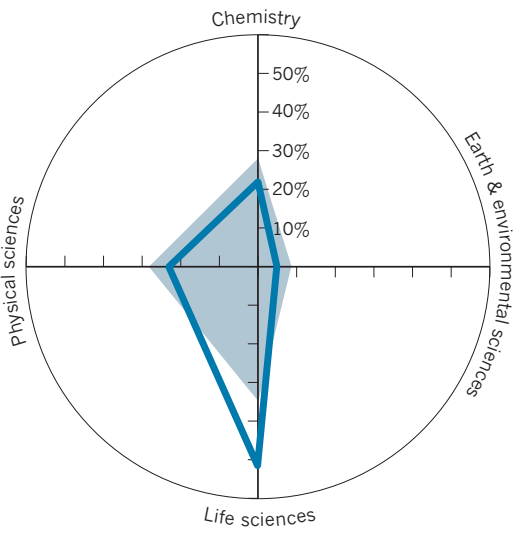

. Office for National Statistics (2016)

2. Eurostat (2015)

Higher Education Statistics Agency (2016)

. United States Patent and Trademark Office (2016) 
to London from Europe. About half of the hundreds of applications for the Crick's graduate research positions and group leader posts, which were received after the Brexit referendum, have come from citizens of other EU countries.

Still, it is widely acknowledged by scientists in London that Brexit creates uncertainty. The deadline for agreeing to the terms of the UK's exit deal is in March 2019. Until the details of the UK's new status are firmly established, the ambiguity of the eventual outcome will weigh on the London research community.

A 'hard' Brexit, whereby EU citizens would no longer be able to freely enter and work in the UK - and UK scientists would very probably lose the right to apply for EU funds - has seemed less likely since the Conservative party lost its parliamentary majority in June. But that hasn't stopped nearby EU countries from eyeing a possible boost to their stock of scientific talent from researchers based in the UK. Science Foundation Ireland, a national research funding organization, is now strongly emphasizing collaboration between Irish and UK scientists, with the intention of being seen as an obvious place to move.

France's president, Emmanuel Macron, has announced planned regulations that would encourage high-tech spin-offs to put down roots in Paris, including making it easier to hire and fire workers and offer stock options to staff. Such changes could draw many companies from London.

Those charged with attracting research to London are not panicking yet - a 'soft' Brexit might retain UK researchers' access to EU programmes. In any case, MedCity's Haywood admits that institutions are thinking of counterstrategies to keep innovation in the city, but also emphasizes that London's core strengths are not going away any time soon.

David Gann, Imperial College's vicepresident (innovation), who leads the institution's innovation strategy, does not see innovation in zero-sum terms. "Science has been in the culture and in the minds of people in London for half a millennium, at least," he says.

\section{INTER-CITY COLLABORATIONS}

This map shows the top ten collaborations between pairs of institutions based in London. Six institutions account for the ten most productive partnerships in the index, ranked by their collaboration score (CS), which sums the share of authorship for each institution in papers they have co-authored. Bubbles represent an institution's total contribution to the share of authorship in the index, measured by weighted fractional count (WFC).



\section{TOP IO INSTITUTIONS IN LONDON}

\begin{tabular}{|c|c|c|c|c|c|}
\hline RANK & INSTITUTION & WFC 2012 & WFC 2016 & $\begin{array}{l}\text { CHANGE IN WFC } \\
2012-2016\end{array}$ & AC 2016 \\
\hline 1 & Imperial College London & 170.8 & 194.7 & $14 \%$ & 858 \\
\hline 2 & University College London & 194.7 & 187.6 & $-4 \%$ & 1,012 \\
\hline 3 & King's College London & 73.6 & 70.3 & $-4 \%$ & 337 \\
\hline 4 & Medical Research Council & 58.4 & 54.6 & $-7 \%$ & 250 \\
\hline 5 & Queen Mary University of London & 37.5 & 43.3 & $15 \%$ & 277 \\
\hline 6 & AstraZeneca plc & 12.4 & 22.8 & $84 \%$ & 80 \\
\hline 7 & GlaxoSmithKline plc & 16.6 & 17.7 & $7 \%$ & 74 \\
\hline 8 & Cancer Research UK & 20.4 & 13.6 & $-33 \%$ & 119 \\
\hline 9 & Institute of Cancer Research & 15.3 & 9.8 & $-36 \%$ & 43 \\
\hline 10 & Birkbeck, University of London & 7.2 & 8.0 & $12 \%$ & 45 \\
\hline
\end{tabular}

